\title{
Changes of the aerodynamic characteristics of a flux site after an extensive windthrow
}

\author{
Bruna R. F. Oliveira ${ }^{1}$, Jan J. Keizer ${ }^{1}$, Thomas Foken ${ }^{2}$ \\ $5 \quad{ }^{1}$ Earth surface processes team, Center for Environmental and Marine Studies (CESAM), Department of Environment and \\ Planning, University of Aveiro, Aveiro, Portugal \\ ${ }^{2}$ Bayreuth Center of Ecology and Environmental Research (BayCEER), University of Bayreuth, Bayreuth, Germany \\ Correspondence to: Thomas Foken (thomas.foken@uni-bayreuth.de)
}

10 Abstract. A maritime pine plantation in Central Portugal that has been continuously monitored using the eddy-covariance technique for carbon fluxes since a wildfire in 2017, was significantly affected by two storms during December 2019 that resulted in a large-sale windthrow. This study analyses the impacts of this windthrow on the aerodynamic characteristics of zero-plane displacement and roughness length, and, ultimately, their implications for the turbulent fluxes. The turbulent fluxes were only affected to a minor degree by the windthrow, but the footprint area of the flux tower changed markedly, so that the target area of the measurements had to be re-determined.

Keywords: windthrow, eddy covariance, aerodynamic characteristics, carbon dioxide fluxes

\section{Introduction}

Heterogeneous surfaces have an influence on turbulent energy and mass fluxes (Stoy et al., 2013). For example, increased fluxes have been found at forest edges (Klaassen et al., 2002). Large-eddy simulations have suggested that fluxes are at their maximum at a distance of about 10 times the canopy height from the forest edge (Kanani-Sühring and Raasch, 2015;Dupont and Brunet, 2009). An increase in flux could also be associated with an increase in stand heterogeneity (Foken et al., 2021). An intrinsic limitation of the cited studies is that they cannot find a suitable measure of heterogeneity that is correlated with turbulent fluxes.

The post-wildfire flux site in Vila de Rei, central Portugal (Oliveira et al., 2021) offered an opportunity to study the impacts of an abrupt change in aerodynamic characteristics without a concomitant change in stand heterogeneity, virtually like a laboratory experiment. Namely, the storms Elsa and Fabien caused an extensive windthrow of the - dead - burnt maritime pine trees between 19 and 21 of December 2019, 28 months after the wildfire, while the tumbled trees remained on the ground afterwards (Figure 1). This prompted us to study the changes in the zero-plane displacement and the roughness parameter before and after the windthrow. Furthermore, we decided to analyse if the changes in these two aerodynamic characteristics also affected carbon dioxide fluxes. This question, however, is difficult to answer in this particular case. Roughly two years after the wildfire, the pine ecosystem was still in its initial phase of post-fire vegetation recovery, so that an increase in $\mathrm{CO}_{2}$ uptake is to be expected between the period before and the period after the windthrow, regardless of the aerodynamic changes. Nevertheless, a change in zero-plane displacement can have a significant impact on the ObukhovLettau stability parameter $(z-d) / L$ (z: measurement height, d: zero-plane displacement, L: Obukhov length, Foken and Börngen, 2021), which, in turn, is crucial to the correction and assessment of carbon dioxide fluxes. 


\subsection{Measurement site and measurements}

The measurement area, instrumentation, and data processing were comprehensively described by Oliveira et al. (2021), so only the details essential for this study are given below.

The study area is located $8 \mathrm{~km}$ to the southwest of the Vila de Rei municipality, N39 $37^{\prime} \mathrm{W}^{\circ} 8^{\circ} 06^{\prime}$, in a Mediterranean climate zone. The wildfire affecting the area burned 1250 ha of woodlands. The measurement site included a plateau of sedimentary sandstone deposits, located at an elevation of $250 \mathrm{~m}$ a.s.1. and with slopes of up to $5^{\circ}$ over an extension of roughly 10 ha. The crowns of the bulk of the burned maritime pine (Pinus pinaster Ait.) were fully consumed by the fire but their trunks of approximately $8 \mathrm{~m}$ height remained standing. This canopy height and a zero-plane displacement of $3.8 \mathrm{~m}$ were used in all calculations in Oliveira et al. (2021). The localized patches of burned eucalypt trees and stands had a canopy height of approximately $4 \mathrm{~m}$. In the relatively open part of the pine area, a $12 \mathrm{~m}$-high slim tower was installed at the end of September 2017 and equipped with an eddy-covariance system at $11.8 \mathrm{~m}$, including a sonic anemometer CSAT3 (Campbell Sci. Inc.) and a LI-7500A gas analyzer (Licor Biosciences), see Figure 1. The fluxes of momentum, sensible heat, latent heat, and carbon dioxide were analyzed with the eddy-covariance method (Aubinet et al., 2012). The data of the eddycovariance system were calculated with the Campbell Sci. Inc. EasyFlux DL software for a quick inspection in the field, while all further calculations were done with the software package TK3 (Mauder and Foken, 2015).
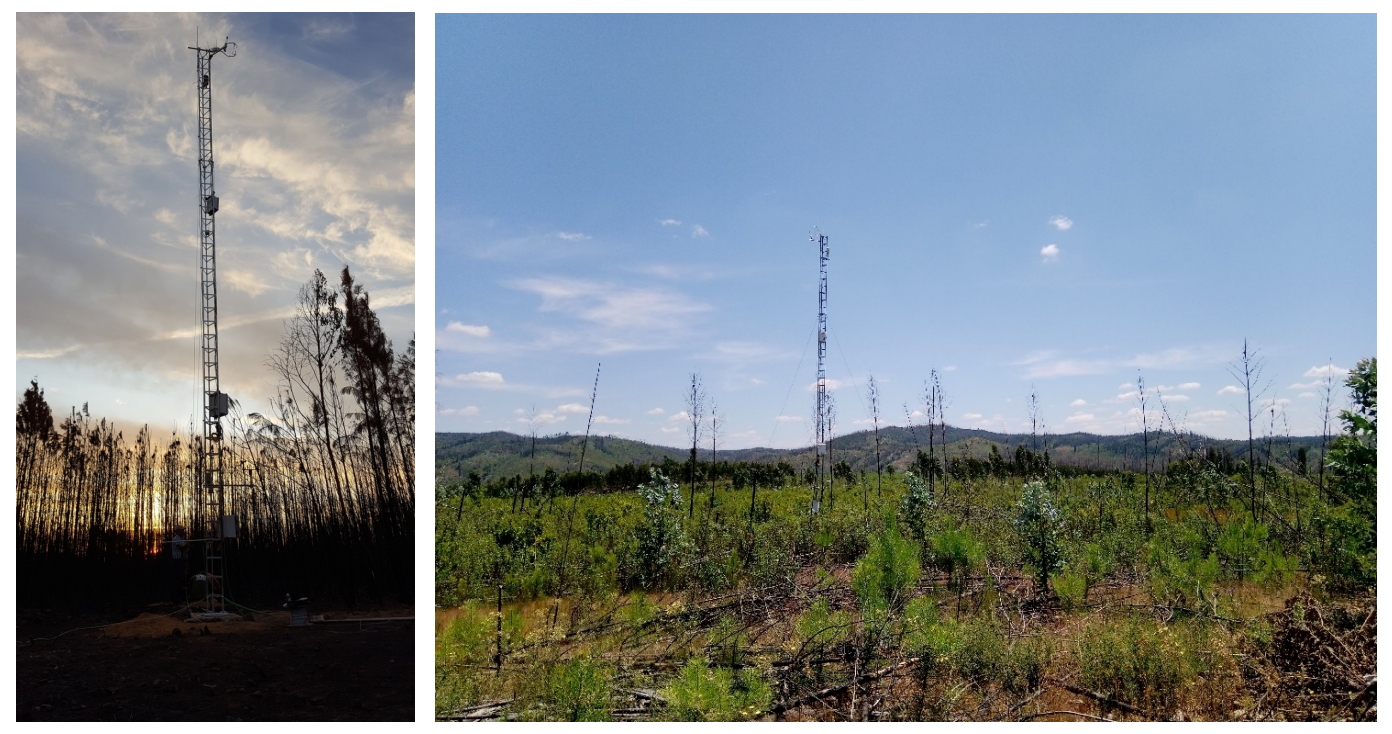

Figure 1: $12 \mathrm{~m}$ slim tower with eddy-covariance system at the burnt Pinus pinaster plantation (left: Photograph: J.J.

Keizer, 22 September 2017) and the plantation after the windthrow (right: Photograph: J.J. Keizer, 20 June 2020) 


\subsection{Aerodynamic characteristics}

The starting point for the analysis of the aerodynamic conditions was the logarithmic wind profile. In order to exclude influences due to the stability of the stratification, the analysis was limited to neutral cases $(-0.05 \leq z / L \leq 0.1)$. The profile equation contains the measured quantities wind speed $u$ and friction velocity $u_{*}$ and the two unknowns of zero-plane displacement $d$ and roughness length $z_{0}$ (Arya, 2001;Foken, 2017;Stull, 1988)

$\frac{u(z-d)}{u_{*}}=\frac{1}{\kappa} \ln \frac{z-d}{z_{0}}$

with the von Kármán constant $\kappa=0.4$. If wind speeds are measured at different heights, both unknowns can be determined iteratively. In the present case, however, measurements were only available at $11.8 \mathrm{~m}$ height, so one of the two parameters must be estimated. It is common in such cases to estimate the zero-plane displacement, in particular as equal to two-thirds of the stand height $\left(d=0.666 z_{c}\right)$, as is implemented in calculation programs for eddy-covariance measurements. In reality, however, this multiplication factor varies in the range from 0.5 to 0.8 , depending on stand structure and, hence, on plant development over the course of a year (Maurer et al., 2015) as well as wind speed (Marunitsch, 1971). Often the value

75 attributed to this factor depends strongly on the experience of the observer. Oliveira et al. (2021) used as canopy height $z_{\mathrm{c}}$ $=7.6 \mathrm{~m}$, as zero-plane displacement $d=3.8 \mathrm{~m}=0.5 z_{\mathrm{c}}$, and as roughness length $z_{0}=0.4 \mathrm{~m}$ for the period before the windthrow. For the investigations after the windthrow a canopy height $z_{\mathrm{c}}=2.7 \mathrm{~m}$ and a zero-plane displacement $d=1.8 \mathrm{~m}=0.666 z_{\mathrm{c}}$ were assumed.

The roughness length and the dimensionless wind profile $u(z-d) / u_{*}$ are typically used as measures of the roughness of

80 surface and the friction on the surface. In addition, it is useful to determine the so-called integral turbulence characteristic from the standard deviation of the vertical wind velocity and friction velocity $\sigma_{w} / u_{*}$, which has a value of about 1.25 in the neutral case (Foken, 2017; Garratt, 1992) and of 1.1 for measurements close above the canopy (Finnigan et al., 2009). It can, however, attain higher values under the influence of high roughness (Foken and Leclerc, 2004).

Roughness length can be determined by two methods that are nearly independent. The first method is through Eq. (1) for a given $z-d$ :

$z_{0}=\frac{z-d}{\mathrm{e}^{\kappa u(z-d) / u_{*}}}$

The second method is based on the following relation (Panofsky, 1984), with $\sigma_{w} / u_{*}=1.25$ :

$\frac{\sigma_{w}}{u(z-d)}=\frac{1.25 \kappa}{\ln \left(z-d / z_{0}\right)}$

From Eq. (3), roughness length then follows as: 


\subsection{Influence of the changes in aerodynamic characteristics on carbon dioxide fluxes}

All relevant software packages for the calculation of the carbon dioxide fluxes use, besides measurement height, canopy height and zero-plane displacement as input parameters. These parameters are mainly needed to determine the ObukhovLettau stability parameter $(z-d) / L$, with the Obukhov length:

$L=-\frac{u_{*}^{3}}{\kappa \cdot \frac{g}{T} \cdot \frac{Q_{H}}{\rho c_{p}}}$

with the gravity accelaration $g$, the temperature $T$, the sensible heat flux $Q_{\mathrm{H}}$, the air density $\rho$, and the specific heat for constant pressure $c_{\mathrm{p}}$.

The Obukhov-Lettau stability parameter, in turn, is crucial for: (i) spectral correction in the high-frequency spectrum (Garratt et al., 2020;Moore, 1986); (ii) stability-dependent turbulence characteristics in quality control (Foken and Wichura, 1996); and (iii) determination of the footprint (Leclerc and Foken, 2014). Therefore, this study also addresses the implications of the windthow-induced changes in aerodynamics for these three aspects.

The model spectra for frequency correction (e.g. Kaimal et al., 1972) are stability dependent (i), while the integral characteristics used for data quality analysis (if not limited to the neutral case as in Eq. (3)), are also stability dependent (ii), e.g. according to Panofsky et al. (1977):

$\sigma_{w} / u_{*}=1.3\left(1-2 \frac{z-d}{L}\right)^{1 / 3}$

To determine the source area of $\mathrm{CO}_{2}$-flux measurements, footprint models (iii) are used, and the input parameters are mainly wind speed, roughness length and stability. In the present case, the widely used model according to Kormann and Meixner (2001) was applied.

Further explanations of the corresponding equations and models shall be omitted, since they are described comprehensively in the literature (Foken et al., 2012; Mauder et al., 2021). Furthermore, supplementary information was provided in the prior publication (Oliveira et al., 2021).

\section{Results}

\subsection{Aerodynamic characteristics}

A climatology of the wind field would require a minimum of 10 years of data, even if a period of 30 years is the standard. In other words, changes in the wind field before and after the windthrow could simply reflect inter-annual variation. Nevertheless, it was striking that the median wind speed was higher after than before the windthrow in eight of the twelve wind sectors (Figure 2), suggesting that the windthrow provoked a generalized decrease in zero-plane displacement. 


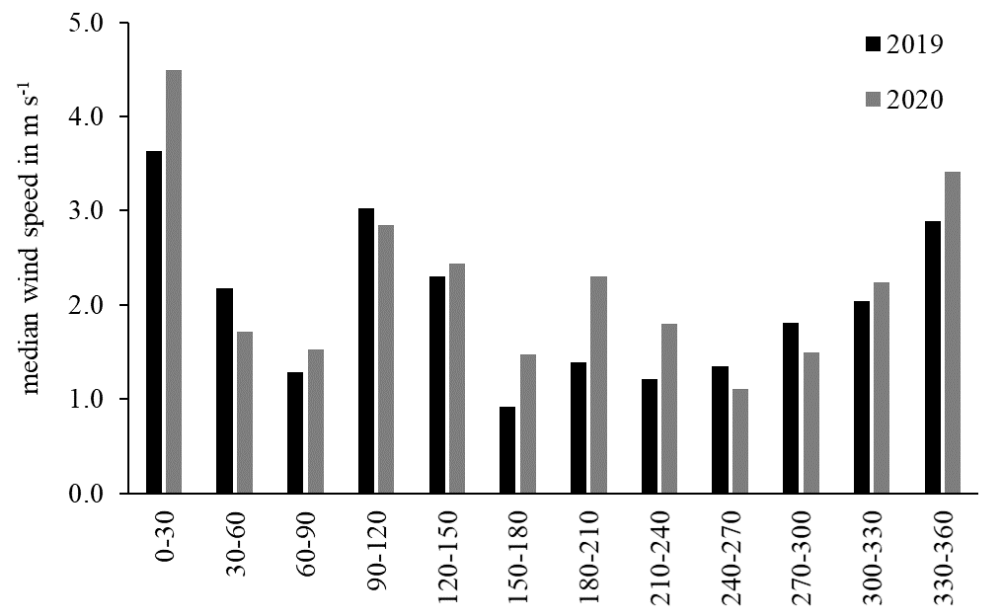

Figure 2: Median wind speed from the 12 wind direction sectors for the periods of May to August 2019 and 2020

According to Table 1, the ratio $u(z-d) / u_{*}$ before and after the windthrow changed roughly from 5-6 to 8-9, corresponding to about $60 \%$ increase. In the NE sector, the change was smaller but the ratio was already comparatively high before the windthrow. Assuming a value for $z-d$ of $8 \mathrm{~m}$ before and $10 \mathrm{~m}$ after the windthrow, the effective measuring heights were 8 $\mathrm{m}$ and $10 \mathrm{~m}$, respectively.

The roughness length showed a decrease after the windthrow (Table 2). Especially after the windthrow, the roughness lengths agreed relatively well between the two methods. Generally, the roughness length was greatest in the SE sector.

The ratio $\sigma_{w} / u_{*}$ showed the expected values (Table 3 ). The values were slightly lower before than after the windthrow, in line with the smaller distance between measurement height and the top of the canopy. The NE and the W-NW sectors revealed comparatively large roughnesses both before and after the windthrow. The wind sectors highlighted in Tables 1-3 are illustrated in Figure 3.

Table 1: The median of the ratio $u(z-d) / u_{*}$ before $(z-d=8 \mathrm{~m})$ and after $(z-d=10 \mathrm{~m})$ the windthrow for a nearly

nine-month period (22 Dec. 2018 to 30 Sept. 2019 and 22 Dec. 2019 to 30 Sept. 2020)

\begin{tabular}{lllllllllllll}
\hline & $0-$ & & & $90-$ & $120-$ & $150-$ & $180-$ & $210-$ & $240-$ & $270-$ & $300-$ & $330-$ \\
Wind direction & 30 & $30-60$ & $60-90$ & 120 & 150 & 180 & 210 & 240 & 270 & 300 & 330 & 360 \\
\hline Before windthrow & 5.25 & 6.69 & 7.38 & 5.97 & 5.15 & 5.26 & 6.48 & 5.77 & 5.79 & 6.98 & 6.26 & 5.51 \\
After windthrow & 8.47 & 8.74 & 9.52 & 7.64 & 6.60 & 8.27 & 9.19 & 9.16 & 8.71 & 10.13 & 8.51 & 8.03 \\
\hline
\end{tabular}


https://doi.org/10.5194/bg-2022-8

Preprint. Discussion started: 24 January 2022

(c) Author(s) 2022. CC BY 4.0 License.

Table 2: The median roughness lengths $z_{0}$ in $\mathrm{m}$ before $(z-d=8 \mathrm{~m})$ and after $(z-d=10 \mathrm{~m})$ the windthrow for the nearly nine-month periods, computed following Eqs. (2) and (4)

\begin{tabular}{lccccccccccccc}
\hline Wind direction & & $\begin{array}{l}30- \\
60\end{array}$ & $\begin{array}{l}60- \\
90\end{array}$ & $\begin{array}{l}90- \\
120\end{array}$ & $\begin{array}{l}120- \\
150\end{array}$ & $\begin{array}{l}150- \\
180\end{array}$ & $\begin{array}{l}180- \\
210\end{array}$ & $\begin{array}{l}210- \\
240\end{array}$ & $\begin{array}{l}240- \\
270\end{array}$ & $\begin{array}{l}270- \\
300\end{array}$ & $\begin{array}{l}300- \\
330\end{array}$ & $\begin{array}{l}330- \\
360\end{array}$ \\
\hline Before windthrow & & & & & & & & & & & & \\
Eq. 2 & 0.98 & 0.55 & 0.42 & 0.73 & 1.02 & 0.98 & 0.60 & 0.80 & 0.79 & 0.49 & 0.65 & 0.88 \\
Eq. 4 & 0.89 & 0.73 & 0.38 & 0.59 & 0.86 & 0.81 & 0.48 & 0.55 & 0.65 & 0.50 & 0.61 & 0.79 \\
\hline After windthrow & & & & & & & & & & & & \\
Eq. 2 & 0.34 & 0.30 & 0.22 & 0.47 & 0.71 & 0.37 & 0.25 & 0.26 & 0.31 & 0.17 & 0.33 & 0.40 \\
Eq. 4 & 0.27 & 0.40 & 0.26 & 0.36 & 0.57 & 0.41 & 0.23 & 0.22 & 0.28 & 0.22 & 0.34 & 0.34 \\
\hline
\end{tabular}

Table 3: The median ratio $\sigma_{w} / u_{*}$ before $(z-d=8 \mathrm{~m})$ and after $(z-d=10 \mathrm{~m})$ the windthrow for the nearly nine-month periods

\begin{tabular}{lllllllllllll}
\hline & $0-$ & & & $90-$ & $120-$ & $150-$ & $180-$ & $210-$ & $240-$ & $270-$ & $300-$ & $330-$ \\
Wind direction & 30 & $30-60$ & $60-90$ & 120 & 150 & 180 & 210 & 240 & 270 & 300 & 330 & 360 \\
\hline Before windthrow & 1.20 & 1.39 & 1.21 & 1.15 & 1.15 & 1.15 & 1.15 & 1.07 & 1.15 & 1.26 & 1.22 & 1.19 \\
After windthrow & 1.17 & 1.36 & 1.31 & 1.15 & 1.15 & 1.30 & 1.22 & 1.21 & 1.22 & 1.33 & 1.26 & 1.19 \\
\hline
\end{tabular}

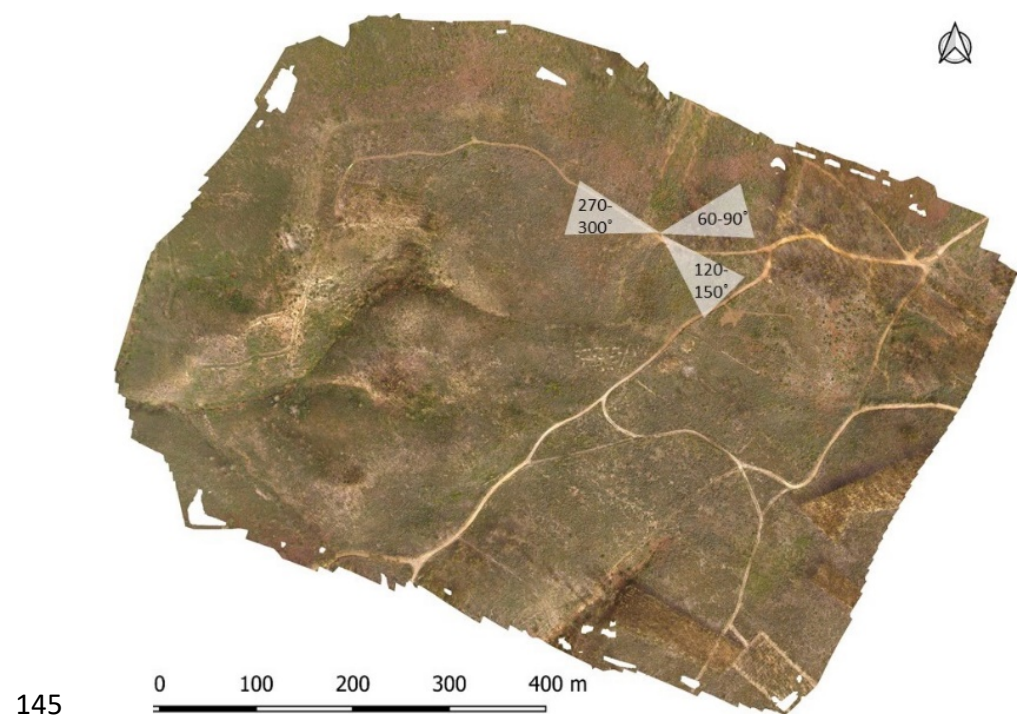

Figure 3: Unmanned Aerial System (UAS)-based ortho-photomap with the most disturbed wind sectors. Image from 23 February 2021 by B.R.F. Oliveira. 
Carbon dioxide fluxes were evaluated for the months of May to August 2019 and 2020 to investigate the impacts of the windthrow-induced changes in the stability parameter. This was done without gap-filling. Of course, the comparison between before- and after-windthrow fluxes is not straightforward, because of the differences in weather conditions as well as in postfire ecoystem recovery between the two periods. Therefore, the spectral correction and data quality analysis were only done for the 2020 data set, assuming two different zero-plane displacements.

Examination of the ratio $\sigma_{w} / u_{*}$ showed minor and not relevant differences for $z-d=8 \mathrm{~m}$ before the wind break and $z-d=$ $10 \mathrm{~m} \mathrm{~m}$ after the windthrow. The median differed by only $0.4 \%$ and, hence, did not affect the quality flagging. Also the difference with and without spectral correction was reduced, even if slightly over $1 \%$.

A similar result was obtained for the $\mathrm{CO}_{2}$ and net ecosystem exchange (NEE) fluxes. As shown in Figure 4, the differences in NEE fluxes with and without stratification-dependent spectral correction was about $1 \%$ for the two different effective measurement heights $8 \mathrm{~m}$ and $10 \mathrm{~m}$. The median values of the spectrally corrected fluxes differed less than $0.5 \%$ between both measurement heights. Furthermore, the scatter around these median values was reduced.

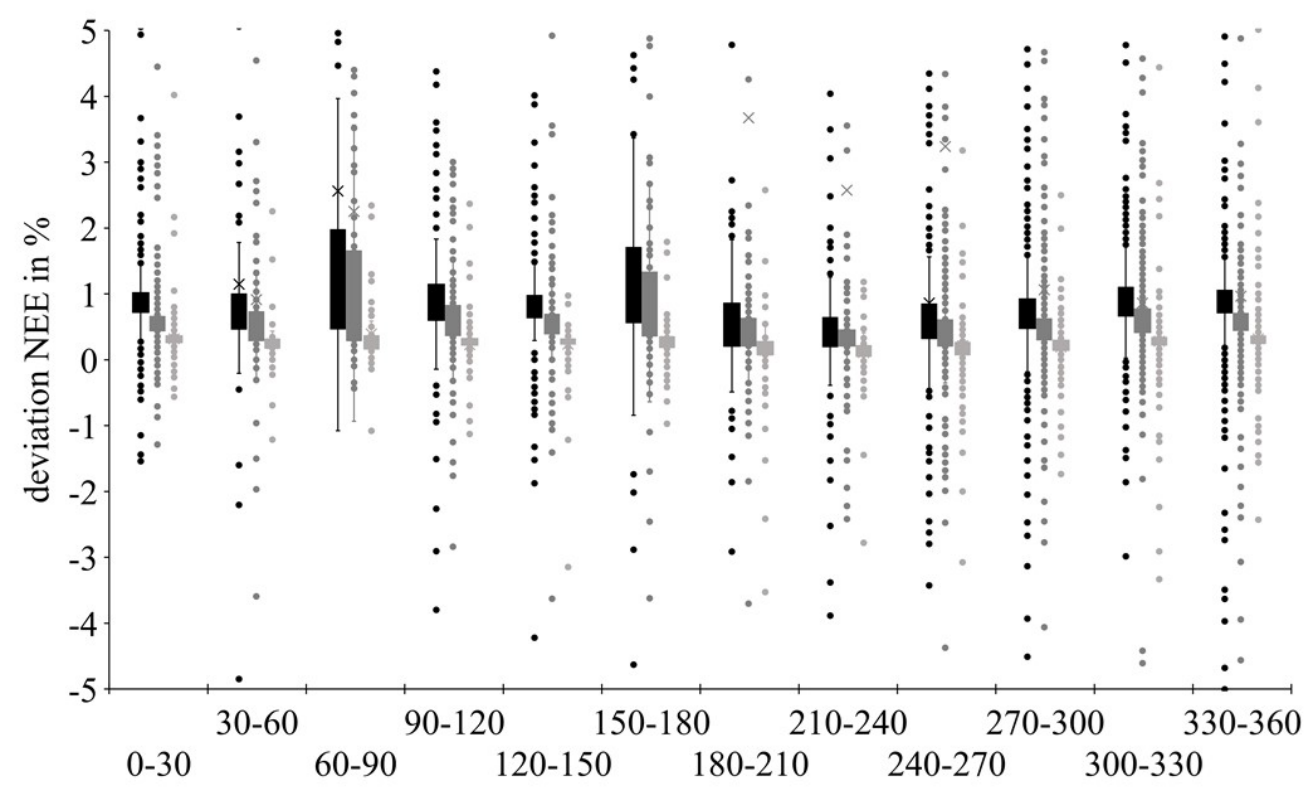

-2020, $z-d=8 \mathrm{~m}$, Moore T vs. F $2020, z-d=10 \mathrm{~m}$, Moore T vs. F $=2020, z-d=8$ vs. $10 \mathrm{~m}$, Moore T

Figure 4: Comparison of the net ecosystem excahnge (NEE) with and without spectral correction for $z-d=8 \mathrm{~m}$ 
More pronounced implications were expected with respect to the size of the source area. Therefore, the target area of burned pine woodland with down wood of charred trunks was calculated with the footprint model (Kormann and Meixner, 2001), analogous to Oliveira et al. (2021). For ther 2020 period, this was done for both values of $z-d=8$ and $z-d=10$ and the assigned roughness lengths of $z_{0}=0.7 \mathrm{~m}$ and $z_{0}=0.3 \mathrm{~m}$ before and after the windthrow, respectively (Figure 5). For comparison, Figure 5 also shows the results for the 2019 period. The differences between the results obtained using $z-d=$ $8 \mathrm{~m}$ and $\mathrm{z}_{0}=0.7 \mathrm{~m}$ for both periods were mainly due to the differences in wind regimes during the 2019- and 2020-periods, as shown in Figure 2. The differences between the results obtained for the 2020-period using the different aerodynamic parameter values of before and after the windthrowwere relevant. The footprint was substantially larger for the post- than pre-windthrow parameter values, while the number of cases with the target area in the footprint was clearly smaller.

The enlargement of the footprint can be prevented by reducing the measuring height. This is usually not possible with longterm measurement programmes with a permanently installed mast, because then you get flow distortion problems due to the mast. Hydraulic lifted masts are hardly ever used in such programmes (Kolle et al., 2021). To simulate this case, Figure 5 shows the footprint for a measurement height of $9.8 \mathrm{~m}$ with a reduction of the wind speed by $10 \%\left(z-d=8 \mathrm{~m}, z_{0}=0.3 \mathrm{~m}\right)$. The change in measurement height leads to an almost identical distribution of the footprint as before the windthrow in 2019.

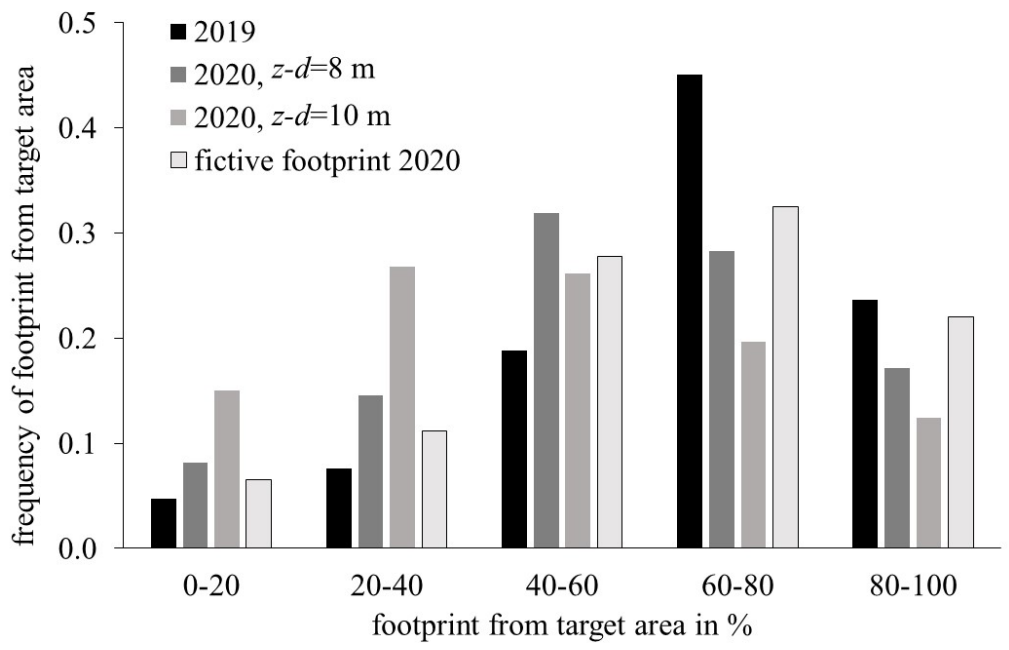

Figure 5: Percentage of the target area (burnt maritime pine woodland) classes in the footprint area of the eddycovariance measurements from May to August 2019 and 2020, using $z-d=8 \mathrm{~m}$ for both periods and $z-d=10 \mathrm{~m}$ for the 2020-period. Furthermore, the fictive footprint for a measurement height of $9.8 \mathrm{~m}$ with a reduction of the wind speed by $10 \%\left(z-d=8 \mathrm{~m}, z_{0}=0.3 \mathrm{~m}\right)$ is shown.

\section{Discussion}


Before the windthrow, the wind profile was lifted up by the displacement height. After the windthrow, the tumbled pine trees determined the roughness. However, the roughness was slightly lower after windthrow, while the typical directional dependence was largely preserved. The two determination methods produced consistent results. Worth stressing is that the two methods (Eq. 2 and 4) are not completely independent, because they can be transformed into each other.

The $120^{\circ}-150^{\circ}$ sector had a comparatively high roughness both before and after the windthrow. This was probably due to the greater slope angle or the influence of the tower. By contrast, the $30^{\circ}-60^{\circ}$ and $270^{\circ}-300^{\circ}$ sectors were affected by additional mechanical turbulence, as was also found by Oliveira et al. (2021) for the first post-fire year. This is illustrated in Figure 6, using Eq. (1), and shows the dimensionless wind profile as a function of $z-d$ for different roughness lengths. Also the median values for the $30^{\circ}$ sectors were included in the plot. Because of the physical correlation between all quantities, the plot cannot be used to determine the zero-plane displacement (as referred earlier) but it does indicate the sectors where the assumed parameter values seem appropriate.

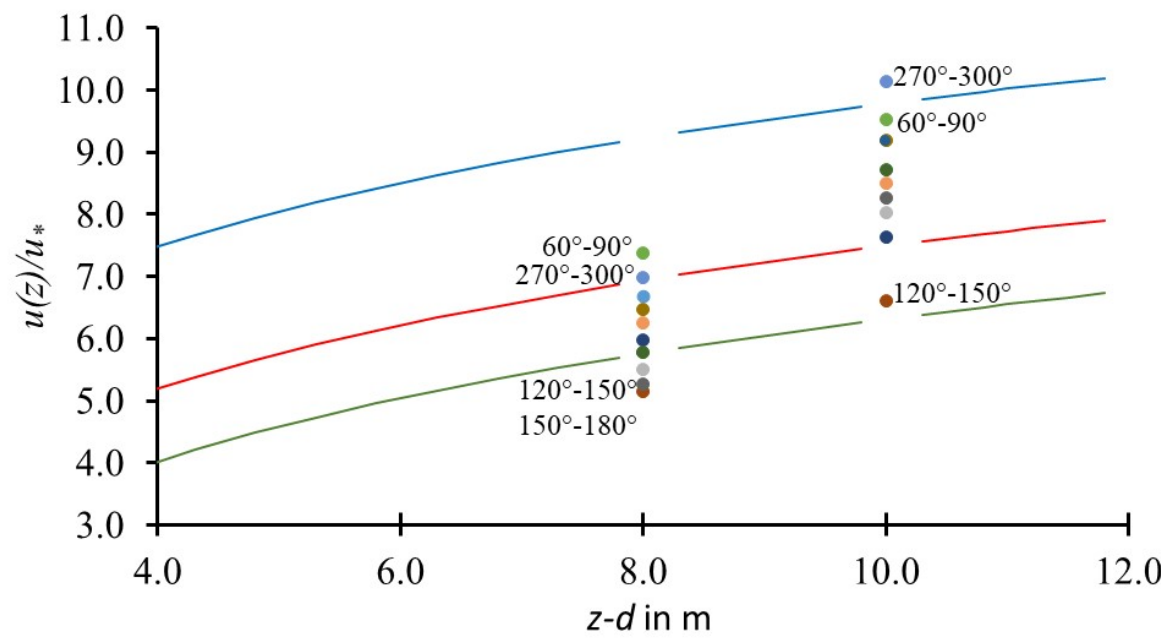

$\begin{array}{llll}-u / u_{*}\left(z_{0}=0.2 \mathrm{~m}\right) & -u / u_{*}\left(z_{0}=0.5 \mathrm{~m}\right) & -u / u_{*}\left(z_{0}=0.8 \mathrm{~m}\right) & \cdot 0-30 \\ \cdot 30-60 & \bullet 60-90 & \bullet 90-120 & \bullet 120-150 \\ \cdot 150-180 & \bullet 180-210 & \bullet 210-240 & \bullet 240-270\end{array}$

Figure 6: Normalized wind profile in dependence on the displacement height given as $z-d(z=11.8 \mathrm{~m})$ and the roughness length $z_{0}$. Median values for wind sectors are plotted for $z-d=8 \mathrm{~m}$ (before the wind break) and $z-d=$ $10 \mathrm{~m}$ (after the wind break).

The ratio $\sigma_{w} / u_{*}$ was largely constant at neutral stratification and only revealed a small stability dependence. This parameter can be used to detect obstacles at larger distances (Foken and Leclerc, 2004) or near the anemometer, for example. Even single standing trees can generate noticeable mechanical turbulence (Jegede and Foken, 1999). In the $60^{\circ}-90^{\circ}$ sector, the mechanical turbulence was probably due to eucalypt trees, whose crowns were quickly re-established after the wildfire by 
resprouting. The increased values in the $270^{\circ}-330^{\circ}$ sector can only be explained by slope parallel flow, see Oliveira et al. (2021), Figure 1.

Evaluation of both dimensionless parameters, together with an assessment of terrain and post-fire vegetation recovery, suggested that the assumptions in (Oliveira et al., 2021) of $z-d=8 \mathrm{~m}$ and $z_{0}=0.4 \mathrm{~m}$ were adequate for most wind sectors for the post-fire and pre-windthrow period. However, a value for $z_{0}=0.7 \mathrm{~m}$ would have more appropriate for the calculation of the footprint. Likewise, the assumptions of $z-d=10 \mathrm{~m}$ and $z_{0}=0.3 \mathrm{~m}$ were appropriate for most wind sectors for the post-windthrow period. These assumptions, however, were less approriate for three sectors highlighted in Table 3 , most notably after the windthrow, where no increase in the wind speed (Figure 2) could be detected. The greater variability in roughness after the windthrow can be explained by the higher wind speeds which, in turn, were due to the increase in effective measurement height resulting from the larger distance to the canopy height.

\subsection{Influence on Carbon-dioxide fluxes}

The investigations carried out clearly showed that due to the different values of the effective measurement height $z-d$ before and after the wind break in the determination of the Obukhov-Lettau stability parameter, no influence on the quality flags and the measurement of the net ecosytem exchange could be detected that would have even come close to the typical error range.

By contrast, however, the footprint area increased markedly due to the change in roughness and possibly also wind speed. The difference would probably not have been as large if a slightly better value of $z_{0}=0.5 \mathrm{~m}$ had been assumed before the windthrow. The increase in footprint area also implied a decrease of the target areas in the footprint. In case target areas differ markedly from non-target areas in terms of carbon dioxide fluxes, the change in aerodynamic conditions would substantially affect flux measurements. At the present study site, this is probably not the case, as the non-target areas mainly differ from the target areas by their greater slope angles and not the burned forest.

\section{Conclusions}

The windthrow at the end of 2019 had a significant impact on the aerodynamics of the study area. The present analysis addressed dimensionless turbulence characteristics and focused on the parameters of roughness length and zero-plane displacement. Since both parameters are not independent, either the zero-plane displacement or the roughness length must be specified a priori. For the first post-fire year, Oliveira et al. (2021) selected a $d=3.8 \mathrm{~m}=0.5 z_{\mathrm{c}}(z-d=8 \mathrm{~m})$, justified by the open character of the burnt pine stand due to the complete consumption of most pine crowns by the wildfire. The authors' assumption of $\mathrm{z}_{0}=0.4 \mathrm{~m}$, however, should be revised to $z_{0}=0.7 \mathrm{~m}$.

The initial assumption of this study of $z-d=10 \mathrm{~m}$ and a roughness length of $z_{0}=0.3 \mathrm{~m}$ for the post-windthrow period continues to seem reasonable as well.. This implied that the windthrow drastically changed aerodynamic site conditions. The increase in $\sigma_{w} / u_{*}$ provided a clear indication that the distance between measurement height and canopy height had increased significantly after the windthrow. 
The present study confirmed the disturbances in specific wind sectors signalled by Oliveira et al. (2021). The disturbances in the NE and NW sectors could be assigned to terrain characteristics. According to Figure 6, a change in zero-plane displacement in this sector would not result in an improvement. If coordinate rotation is performed by means of double rotation (Kaimal and Finnigan, 1994), the problem is hardly relevant for the measurements; however, when it is done by means of planar fit rotation (Wilczak et al., 2001), the disturbed sector would have to be rotated separately.

The change in aerodynamic conditions due to the windthrow did not have marked impacts on the calculation of the carbon dioxide fluxes, but it did substantially increase the footprint area. In the present case, this increase in footprint area implied the inclusion of sloping terrain but with essentially the same pre- and post-fire vegetation cover as the realtively flat target area, so that the implications are expected to be minor. The present windthrow occurred at a relative early stage of post-fire ecosystem recovery, so that a direct comparison of pre- and post-windthrow carbon dioxide fluxes was considered unwarranted.

Based on the investigation carried out, we generally recommend determining the effective measurement height and the roughness length as precisely as possible when aerodynamic conditions change in order to be able to determine changes in the footprint area. Since areas outside the target area may have an influence on the fluxes, the quality assessment of the measurement area must be carried out again, taking the footprint into account (Foken et al., 2012;Mauder et al., 2021). Alternatively, the measurement height could be adjusted so that the footprint remains almost identical.

Code and data availability. The program for the calculation of the eddy-covariance data is available (Mauder and Foken, 2015). The daily $\mathrm{CO}_{2}$ flux data are available on Oliveira et al. (2020), other data on request from the first author (bruna.oliveira@ua.pt).

Authors contribution. BRFO was the responsible for ModelEco's project funding and management, and responsible scientist for this Post-doctoral study including fieldwork, data analysis $\left(\mathrm{CO}_{2}\right.$-part), and preparing the structure of the paper and of several of its sections; JJK was responsible for FIRE-C-BUDs' project funding and management, and data analysis (windpart), and revised the paper. TF was the scientific adviser of the project, mainly for the flux part and special aerodynamic analysis, and supported the writing of the paper. The final version of the paper was prepared by all authors.

Competing interests. The authors declare that they have no conflict of interest.

Acknowledgements. This work was supported by the projects ModelEco (PTDC/ASP-SIL/3504/2020), funded by national funds (OE) through FCT/MCTES, and FIRE-C-BUDs (PTDC/AGR-FOR/4143/2014 - POCI-01-0145-FEDER-016780), funded by the FCT/MEC with co-funding by the FEDER, within the PT2020 Partnership Agreement and Compete 2020. Thanks are due to FCT/MCTES for the financial support to CESAM (UIDP/50017/2020+UIDB/50017/2020), through national funds. This publication was funded by the German Research Foundation (DFG) and the University of Bayreuth within the funding program Open Access Publishing.

Edited by: 


\section{References}

Arya, S. P.: Introduction to Micrometeorology, Academic Press, San Diego, 415 pp., 2001.

Aubinet, M., Vesala, T., Papale, D. (eds.): Eddy Covariance: A Practical Guide to Measurement and Data Analysis, Springer, Dordrecht, 438 pp, doi: 10.1007/978-94-007-2351-1, 2012

Dupont, S., and Brunet, Y.: Coherent structures in canopy edge flow: a large-eddy simulation study, J. Fluid Mech., 630, 93-128, doi: 10.1017/S0022112009006739, 2009.

Finnigan, J. J., Shaw, R. H., and Patton, E. G.: Turbulence structure above a vegetation canopy, J. Fluid Mech., 637, 687-424, doi: 10.1017/S0022112009990589, 2009.

Foken, T., and Wichura, B.: Tools for quality assessment of surface-based flux measurements, Agric. For. Meteorol., 78, 83-105, doi: 10.1016/0168-1923(95)02248-1, 1996.

295 Foken, T., and Leclerc, M. Y.: Methods and limitations in validation of footprint models, Agric. For. Meteorol., 127, 223-234, doi: 10.1016/j.agrformet.2004.07.015, 2004.

Foken, T., Leuning, R., Oncley, S. P., Mauder, M., and Aubinet, M.: Corrections and data quality in: Eddy Covariance: A Practical Guide to Measurement and Data Analysis, edited by: Aubinet, M., Vesala, T., and Papale, D., Springer, Dordrecht, Heidelberg, London, New York, 85-131, doi: 10.1007/978-94-007-2351-1_4, 2012.

300 Foken, T.: Micrometeorology, $2^{\text {nd }}$ ed., Springer, Berlin, Heidelberg, 362 pp., doi: 10.1007/978-3-642-25440-6, 2017.

Foken, T., Babel, W., Munger, J. W., Grönholm, T., Vesala, T., and Knohl, A.: Selected breakpoints of net forest carbon uptake at four eddy-covariance sites, Tellus B: Chemical and Physical Meteorology, 73, 1-12, doi: 10.1080/16000889.2021.1915648, 2021.

Foken, T., and Börngen, M.: Lettau's Contribution to the Obukhov Length Scale: A Scientific Historical Study, Boundary-Layer Meteorol., 179, 369-383, doi: 10.1007/s10546-021-00606-4, 2021.

305 Garratt, J., Wilczak, J., Holtslag, A., Schmid, H. P., Grachev, A., Beljaars, A., Foken, T., Chen, F., Fairall, C., Hicks, B., Kusaka, H., Martilli, A., Masson, V., Mauder, M., Oncley, S., Rotach, M., and Tjernström, M.: Commentaries on Top-Cited Boundary-Layer Meteorology Articles, Boundary-Layer Meteorol., 177, 169-188, doi: 10.1007/s10546-020-00563-4, 2020.

Garratt, J. R.: The Atmospheric Boundary Layer, Cambridge University Press, Cambridge, 316 pp., doi, 1992.

Jegede, O. O., and Foken, T.: A study of the internal boundary layer due to a roughness change in neutral conditions observed during the LINEX field campaigns, Theor. Appl. Climat., 62, 31-41, doi: 10.1007/s007040050072, 1999.

Kaimal, J. C., Wyngaard, J. C., Izumi, Y., and Coté, O. R.: Spectral characteristics of surface layer turbulence, Quart. J. Roy. Meteorol. Soc., 98, 563-589, doi: 10.1002/qj.49709841707, 1972.

Kaimal, J. C., and Finnigan, J. J.: Atmospheric Boundary Layer Flows: Their Structure and Measurement, Oxford University Press, New York, NY, 289 pp., doi: 10.1093/oso/9780195062397.001.0001, 1994.

315 Kanani-Sühring, F., and Raasch, S.: Spatial variability of scalar concentrations and fluxes downstream of a clearing-to-forest transition A Large-Eddy Simulation study, Boundary-Layer Meteorol., 155, 1-27, doi: 10.1007/s10546-014-9986-3, 2015.

Klaassen, W., van Breugel, P. B., Moors, E. J., and Nieveen, J. P.: Increased heat fluxes near a forest edge, Theor. Appl. Climat., 72, 231-243, doi, 2002

Kolle, O., Kalthoff, N., Kottmeier, C., and Munger, J. W.: Ground based platforms, in: Springer Handbook of Atmospheric Measurements, edited by: Foken, T., Springer Nature, Switzerland, 155-182, doi: 10.1007/978-3-030-52171-4_6, 2021.

Kormann, R., and Meixner, F. X.: An analytical footprint model for non-neutral stratification, Boundary-Layer Meteorol., 99, 207-224, doi: 10.1023/A:1018991015119, 2001.

Leclerc, M. Y., and Foken, T.: Footprints in Micrometeorology and Ecology, Springer, Heidelberg, New York, Dordrecht, London, XIX, 239 pp., doi: 10.1007/978-3-642-54545-0, 2014.

325 Marunitsch, S. V.: Charakteristiki turbulentnosti v yslovijach lesa po gradientnym i strukturnym nabljudenijam (Turbulence characteristics of gradients in a forest from structure observations), Trudy Gos. Gidrometeorol. Inst., 198, 154-165, doi, 1971.

Mauder, M., and Foken, T.: Eddy-Covariance software TK3, Zenodo, 10.5281/zenodo.20349 doi: 10.5281/zenodo.20349, 2015.

Mauder, M., Foken, T., Aubinet, M., and Ibrom, A.: Eddy-Covariance Measurements, in: Springer Handbook of Atmospheric Measurements, edited by: Foken, T., Springer Nature, Switzerland, 1473-1504, doi: 10.1007/978-3-030-51171-4_55, 2021. 
330 Maurer, K. D., Bohrer, G., Kenny, W. T., and Ivanov, V. Y.: Large-eddy simulations of surface roughness parameter sensitivity to canopy-structure characteristics, Biogeosci., 12, 2533-2548, doi: 10.5194/bg-12-2533-2015, 2015.

Moore, C. J.: Frequency response corrections for eddy correlation systems, Boundary-Layer Meteorol., 37, 17-35, doi: doi:10.1007/BF00122754, 1986.

Oliveira, B. R. F., Keizer, J. J., and Foken, T.: Daily Carbon Dioxide fluxes measured by an eddy-covariance station in a recently burnt Mediterranean pine stand in Central Portugal, PANGAEA, doi: 10.1594/PANGAEA.921281, 2020.

Oliveira, B. R. F., Schaller, C., Keizer, J. J., and Foken, T.: Estimating immediate post-fire carbon fluxes using the eddy-covariance technique, Biogeosci., 18, 285-302, doi: 10.5194/bg-18-285-2021, 2021.

Panofsky, H. A., Tennekes, H., Lenschow, D. H., and Wyngaard, J. C.: The characteristics of turbulent velocity components in the surface layer under convective conditions, Boundary-Layer Meteorol., 11, 355-361, doi: 10.1007/BF02186086, 1977.

340 Panofsky, H. A.: Vertical variation of roughness length at the Boulder Atmospheric Observatory, Boundary-Layer Meteorol., 28, 305308, doi: 10.1007/BF00121309, 1984.

Stoy, P. C., Mauder, M., Foken, T., Marcolla, B., Boegh, E., Ibrom, A., Arain, M. A., Arneth, A., Aurela, M., Bernhofer, C., Cescatti, A., Dellwik, E., Duce, P., Gianelle, D., van Gorsel, E., Kiely, G., Knohl, A., Margolis, H., McCaughey, H., Merbold, L., Montagnani, L., Papale, D., Reichstein, M., Serrano-Ortiz, P., Sottocornola, M., Saunders, M., Spano, D., Vaccari, F., and Varlagin, A.: A data-

345 driven analysis of energy balance closure across FLUXNET research sites: The role of landscape-scale heterogeneity, Agric. For. Meteorol., 171-172, 137-152, doi: 10.1016/j.agrformet.2012.11.004, 2013.

Stull, R. B.: An Introduction to Boundary Layer Meteorology, Kluwer, Dordrecht, 666 pp., doi: 10.1007/978-94-009-3027-8, 1988.

Wilczak, J. M., Oncley, S. P., and Stage, S. A.: Sonic anemometer tilt correction algorithms, Boundary-Layer Meteorol., 99, 127-150, doi: 10.1023/A:1018966204465, 2001. 